\title{
Rats with high left ventricular end-diastolic pressure can be identified by Doppler echocardiography one week after myocardial infarction
}

R.M. Saraiva ${ }^{1}$,

R.M. Kanashiro-Takeuchi ${ }^{2}$,

E.L. Antonio ${ }^{2}$, O. Campos ${ }^{1}$,

P.J.F. Tucci ${ }^{2}$

and V.A. Moisés ${ }^{1}$
${ }^{1}$ Disciplina de Cardiologia, Departamento de Medicina,

${ }^{2}$ Disciplina de Fisiologia Cardiovascular e Respiratória,

Escola Paulista de Medicina, Universidade Federal de São Paulo, São Paulo, SP, Brasil

\section{Correspondence}

V.A. Moisés

Disciplina de Cardiologia

EPM, UNIFESP

Rua Botucatu, 740, 2 andar 04023-900 São Paulo, SP

Brasil

Fax: +55-11-5571-0047

E-mail:vmoises@cardiol.br

Research supported by FAPESP (No. 99/0045-3) and CNPq

(No. 300.692/80-3NV).

R.M. Kanashiro-Takeuchi was

the recipient of a fellowship

from FAPESP.

Received March 16, 2007 Accepted August 3, 2007

\section{Abstract}

The severity of left ventricular (LV) dysfunction in rats with myocardial infarction (MI) varies widely. Because homogeneity in baseline parameters is essential for experimental investigations, a study was conducted to establish whether Doppler echocardiography (DE) could accurately identify animals with high LV end-diastolic pressure as a marker of LV dysfunction soon after MI. Direct measurements of LV end-diastolic pressure were made and DE was performed simultaneously 1 week after surgically induced MI $(\mathrm{N}=16)$ or shamoperation $(\mathrm{N}=17)$ in female Wistar rats $(200$ to $250 \mathrm{~g})$. The ratio of peak early (E) to late (A) diastolic LV filling velocities and the ratio of E velocity to peak early $\left(\mathrm{E}_{\mathrm{m}}\right)$ diastolic myocardial velocity were the best predictors of high LV end-diastolic pressure $(>12 \mathrm{mmHg})$ soon after MI. Cut-off values of 1.77 for the E/A ratio $(\mathrm{P}=0.001)$ identified rats with elevated LV end-diastolic pressure with $90 \%$ sensitivity and $80 \%$ specificity. Cut-off values of 20.4 for the $\mathrm{E} / \mathrm{E}_{\mathrm{m}}$ ratio $(\mathrm{P}=0.0001)$ identified rats with elevated LV end-diastolic pressure with $81.8 \%$ sensitivity and $80 \%$ specificity. Moreover, $\mathrm{E} / \mathrm{A}$ and $\mathrm{E} / \mathrm{E}_{\mathrm{m}}$ ratios were the only echocardiographic parameters independently associated with $\mathrm{LV}$ end-diastolic pressure in multiple linear regression analysis. Therefore, DE identifies rats with high LV end-diastolic pressure soon after MI. These findings have implications for using serial DE in animal selection and in the assessment of their response to experimental therapies.

\section{Introduction}

Experimentally induced myocardial infarction (MI) in rats is commonly used as a heart failure (HF) model in a variety of settings, such as the study of pathophysiology $(1,2)$ or the evaluation of experimental drugs
Key words - Heart failure

- Myocardial infarction

- Echocardiography

- Hemodynamics 
rately the degree of LV function impairment in post-MI rats. One of the consequences of post-MI LV dysfunction is elevated LV enddiastolic pressure (LVEDP). However, the gold standard for assessing LVEDP is invasive hemodynamics, which often results in animal death. Therefore, reliable noninvasive assessment of LVEDP becomes crucial.

Noninvasive assessment of cardiac performance, as obtained by Doppler echocardiography (DE), has the advantage of allowing serial evaluations, which are important for longitudinal studies and for testing therapeutic strategies. Previous studies have shown good correlations between different echocardiographic parameters and LVEDP in rats with MI (9-12). However, these studies assessed animals long after MI, without using concomitant direct intraventricular measurements and, therefore, they did not provide reliable cut-off points for the discrimination of animals in HF soon after MI, the time during which animals are usually randomized to experimental therapies. Therefore, the aim of the present study was to establish the value of noninvasive echocardiographic parameters for identifying high LVEDP in rats soon after MI. The study was performed 7 days after MI to avoid acute high mortality during the first $48 \mathrm{~h}$ after MI surgery and any influence of acute trauma associated with surgery on LV hemodynamics.

\section{Material and Methods}

\section{Animals and production of myocardial infarction}

This investigation conformed to the Guide for the Care and Use of Laboratory Animals published by the US National Institutes of Health (NIH Publication No. 96-23, revised, 1996) and was approved by the Institutional Ethics Committee on Animal Research of our University.

Female Wistar rats (200 to $250 \mathrm{~g}$ ) were submitted to MI as previously described (13).
Briefly, after intraperitoneal anesthesia with $50 \mathrm{mg} / \mathrm{kg}$ ketamine $+10 \mathrm{mg} / \mathrm{kg}$ xylazine, a left thoracotomy was performed. The left anterior descending coronary artery was occluded with a 6-0 polypropylene suture and the thorax was immediately closed. Animals had free access to food and tap water after surgery. Sham animals underwent all the previously described surgical procedures except for left anterior descending coronary artery occlusion.

\section{Hemodynamic evaluation}

Simultaneous hemodynamic and echocardiographic evaluations were performed one week after MI. After anesthesia (as described above), the right carotid artery was cannulated with a fluid-filled PE-50 polyethylene catheter with the distal $0.6 \mathrm{~cm}$ portion made of PE-10 silicone. The tip of the catheter was advanced into the LV cavity and a Biopac TSD 104A pressure transducer was used to obtain intraventricular pressure curves (AcqKnowledge ${ }^{\circledR}$ 3.7.3, Biopac Systems Inc., Goleta, CA, USA). The resonant frequency and the degree of damping of the system were $52 \mathrm{~Hz}$ and 0.69 , respectively, calculated as proposed by Fry (14). LVEDP was measured as the average of the values obtained during a complete respiratory cycle, which usually corresponded to 5 consecutive beats.

\section{Doppler echocardiography}

DE was performed using an HP SONOS 5500 instrument (Philips Medical System, Andover, MA, USA) with a $12-\mathrm{MHz}$ transducer for fundamental imaging. All echocardiographic measurements were made after the tip of the LV catheter was placed inside the LV cavity and circulatory equilibrium had been attained. The time when the echocardiographic parameters were recorded was marked on the hemodynamic tracings to allow hemodynamic and DE measurements 
during the same cardiac cycles. The rats were placed in left lateral decubitus. The images were recorded on videotape and image analysis was performed off-line.

Identification and sizing of myocardial infarction. Infarcts were defined as subjectively identified akinesis or dyskinesis on transverse images obtained at three levels: basal (at the tip of the mitral valve leaflets), middle (at the papillary muscle level), and apical (distal to the papillary muscle but proximal to the cavity cap). To quantify MI size, on each echocardiographic transverse plane, the arc corresponding to the infarcted segments (MI) and the total perimeter of the endocardial border (PE) were measured three times at end diastole, and MI size was calculated as: MI size $(\%)=\mathrm{MI} / \mathrm{PE} \mathrm{x} 100$.

The final MI size of each animal was calculated as the mean of MI size estimated on the three planes (15) and was previously shown to be comparable to that measured by quantitative histological examination $(16,17)$.

Chamber dimensions. At least 5 consecutive beats were recorded from the parasternal short axis view just below the mitral valve to obtain LV internal diameters and wall thickness. The LV end-diastolic (LVDd) and end-systolic diameters (LVDs), $\mathrm{LV}$ anterior and posterior wall thickness in diastole, and the left atrium (LA) anteroposterior systolic diameter were measured using M-mode images.

Left ventricular systolic function. The LV fractional area change (LVFAC) was calculated based on three measurements of the diastolic and systolic areas using twodimensional echocardiography obtained for each of the three transverse planes. The mean value of the three planes was used to calculate the LVFAC as the difference between diastolic and systolic areas divided by the diastolic area expressed as percentage.

Diastolic function. From the 4-chamber view, the pulsed Doppler sample volume was positioned at the tip of the mitral valve leaflets to obtain mitral diastolic flow velocities. From the velocity curves, E wave deceleration time and peak $\mathrm{E}$ and $\mathrm{A}$ velocities were measured, and the E/A ratio was derived. Isovolumic relaxation time, determined as the time elapsed between aortic valve closure and mitral valve opening, was measured by continuous wave Doppler positioned between the left ventricular outflow tract and mitral valve in the apical long axis view.

The myocardial performance index of the LV (LV MPI) was calculated as the sum of isovolumic contraction and relaxation times divided by ejection time (15).

\section{Tissue Doppler imaging}

The apical 4-chamber view was used to obtain tissue Doppler velocity traces of mitral annulus at the septal and lateral levels, as previously described $(9,18)$. Peak early $\left(\mathrm{E}_{\mathrm{m}}\right)$ and late $\left(\mathrm{A}_{\mathrm{m}}\right)$ diastolic and systolic myocardial velocities were obtained from the septal and lateral mitral annulus and averaged for each animal. The $E_{m} / A_{m}$ and $E / E_{m}$ ratios were then calculated.

\section{Post-mortem analysis}

After the hemodynamic and echocardiographic studies, the animals were sacrificed and their hearts were excised. The LV and the right ventricle $(\mathrm{RV})$ were weighed. The $\mathrm{LV}$ and RV weight indices were calculated as the LV or RV weight (in $\mathrm{mg}$ ) divided by body weight (in $\mathrm{g}$ ).

\section{Statistical analysis}

Data are reported as means \pm SEM and statistical significance was determined by the Student $t$-test. Relationships between echocardiographic parameters and LVEDP were determined by Pearson's correlation. Receiver-operating characteristic (ROC) curves were used to determine the overall accuracy of the echocardiographic parameters for predicting LVEDP. All echocardio- 
graphic parameters with a significant linear correlation with LVEDP were included in a multiple linear regression model. The null hypothesis was rejected at $\mathrm{P}<0.05$. All the statistical analyses were carried out using the GraphPad Prism 3.02 (GraphPad Software Inc., San Diego, CA, USA) and StataSE 8.0 software (Stata Corporation, College Station, TX, USA). The echocardiographic measurements in the post-MI rat model used by us display high interobserver agreement, as previously documented (15).

\section{Results}

\section{Animal characteristics}

Two different groups were analyzed in the present study: sham-operated rats (Sham; $\mathrm{N}=17$ ), and rats with 1 week-old MI (MI; N =16). The MI size assessed by DE averaged $26.0 \pm 2.8 \%$ of the LV. Whereas the LV weight index was similar between Sham $(2.06 \pm 0.1 \mathrm{mg} / \mathrm{g})$ and MI $(2.13 \pm 0.04 \mathrm{mg} / \mathrm{g})$ groups, the RV weight index was higher in

Table 1. Doppler echocardiographic characteristics of myocardial infarcted (MI) and sham-operated rats (Sham).

\begin{tabular}{lcc}
\hline & Sham $(\mathrm{N}=17)$ & MI $(\mathrm{N}=16)$ \\
\hline MI size $(\%)$ & - & $26.0 \pm 2.8$ \\
LVDd $(\mathrm{cm})$ & $0.66 \pm 0.02$ & $0.76 \pm 0.03^{*}$ \\
LVDs $(\mathrm{cm})$ & $0.26 \pm 0.02$ & $0.48 \pm 0.05^{*}$ \\
LA $(\mathrm{cm})$ & $0.37 \pm 0.01$ & $0.45 \pm 0.02^{*}$ \\
LVFAC $(\%)$ & $83.6 \pm 1.3$ & $52.7 \pm 13.5^{*}$ \\
DT $(\mathrm{ms})$ & $47.0 \pm 2.1$ & $46.3 \pm 1.7$ \\
IVRT $(\mathrm{ms})$ & $37.9 \pm 2.3$ & $49.1 \pm 2.0^{*}$ \\
E/A & $1.92 \pm 0.07$ & $2.91 \pm 0.40^{*}$ \\
LV MPI & $0.37 \pm 0.03$ & $0.58 \pm 0.03^{*}$ \\
$S_{m}(\mathrm{~cm} / \mathrm{s})$ & $2.90 \pm 0.13$ & $2.37 \pm 0.12^{*}$ \\
$E_{m}(\mathrm{~cm} / \mathrm{s})$ & $3.86 \pm 0.17$ & $3.18 \pm 0.16^{*}$ \\
$A_{m}(\mathrm{~cm} / \mathrm{s})$ & $3.40 \pm 0.23$ & $2.61 \pm 0.15^{*}$ \\
$E_{m} / A_{m}$ & $1.18 \pm 0.07$ & $1.24 \pm 0.06$ \\
E/Em & $17.2 \pm 0.7$ & $23.7 \pm 1.6^{*}$ \\
\end{tabular}

Data are reported as means \pm SEM. LVDd $=$ left ventricular end-diastolic diameter; LVDs = left ventricular end-systolic diameter; LA = left atrium diameter; LVFAC = left ventricular fractional area change; DT = E wave deceleration time; IVRT = isovolumic relaxation time; $\mathrm{E} / \mathrm{A}=$ peak $\mathrm{E}$ and $\mathrm{A}$ velocity ratio; $\mathrm{LV} \mathrm{MPI}=$ left ventricular myocardial performance index; $S_{m}=$ systolic myocardial velocity; $E_{m}=$ early diastolic myocardial velocity; $A_{m}=$ late diastolic myocardial velocity.

${ }^{*} \mathrm{P}<0.05$ compared to sham-operated group (Student $t$-test). the MI group $(0.81 \pm 0.03 \mathrm{mg} / \mathrm{g})$ than in the Sham rats $(0.68 \pm 0.04 \mathrm{mg} / \mathrm{g}, \mathrm{P}=0.01)$. Heart rate during data acquisition was similar for the Sham $(218.0 \pm 8.1 \mathrm{bpm})$ and MI $(204.4 \pm 5.3 \mathrm{bpm})$ groups.

\section{Hemodynamics}

MI was associated with a significant increase in LVEDP (Sham: $6.4 \pm 0.7 \mathrm{mmHg} v \mathrm{~s}$ MI: $14.8 \pm 1.6 \mathrm{mmHg} ; \mathrm{P}<0.0001)$ and a significant decrease in LV systolic pressure (Sham: $121 \pm 4 \mathrm{mmHg}$ vs MI: $107 \pm 5$ $\mathrm{mmHg} ; \mathrm{P}=0.03$ ). High LVEDP was defined as values two standard deviations or more above mean LVEDP in the Sham group (over $12 \mathrm{mmHg}$ ). According to this criterion, only five $(31 \%)$ animals in the MI group had normal LVEDP.

\section{Echocardiography}

Except for the E/A ratio, which was not obtained in $3 \%$ of the animals $(\mathrm{N}=1)$, and LV MPI, which was not obtained in $6 \%$ of the animals $(\mathrm{N}=2)$, all other parameters were obtained in all animals.

There were significant changes in several echocardiographic parameters after MI. Chamber dimensions (LVDd, LVDs, and LA) were increased and the systolic function parameter (LVFAC) was depressed after MI (Table 1). Diastolic function was also altered as shown by an increased E/A ratio (Table 1, Figure 1). At the heart rate studied, both $\mathrm{E}$ and $\mathrm{A}$ waves were easily identified and measured. Tissue Doppler analysis revealed a decrease in systolic and diastolic myocardial velocities (Table 1), whereas the $\mathrm{E} / \mathrm{E}_{\mathrm{m}}$ ratio was increased after MI compared to Sham (Table 1). LV MPI was increased after MI compared to Sham (Table 1).

\section{Echocardiographic predictors of high left ventricular end-diastolic pressure}

Myocardial infarction size. Although 
Pearson's correlation analysis showed a regular and significant correlation between MI size and LVEDP (Table 2), MI size was not a good predictor of high LVEDP in the MI group, as revealed by ROC curve analysis (Table 3).

Chamber dimensions. Pearson's correlation analysis showed significant correlations between $\mathrm{LV}$ chamber dimensions and LVEDP in the MI group (Table 2). However, only LVDd was a significant predictor of high LVEDP by ROC curve analysis (Table 3). LA diameter did not show a significant correlation with LVEDP (Table 2) and lacked significance as a predictor of high LVEDP in the MI group (Table 3).

Left ventricular systolic function. Pearson's correlation analysis showed a significant correlation between LVFAC and LVEDP in the MI group (Table 2). Accordingly, LVFAC was also a significant predictor of high LVEDP by ROC curve analysis (Table 3).

Diastolic function. Among measurements of diastolic function, only the E/A ratio could identify high LVEDP soon after MI (Figure 2, Tables 2 and 3) with high area under ROC curve (Figure 2, Table 3) and good linear correlation (Figure 2, Table 2). On the other hand, E wave deceleration time and isovolumic relaxation time were weak predictors of high LVEDP after MI (Tables 2 and 3).

Although LV MPI was significant higher in the MI group than in Sham animals (Table 1), it proved to be a weak predictor of high LVEDP (Table 3), with no significant correlation with LVEDP (Table 2).

Tissue Doppler imaging. Among tissue Doppler parameters, the $\mathrm{E} / \mathrm{E}_{\mathrm{m}}$ ratio was the only parameter that could identify high LVEDP soon after MI with a large area under the ROC curve (Figure 2, Table 3 ) and a good linear correlation $(\mathrm{r}=0.75, \mathrm{P}=$ 0.0008; Figure 2, Table 2).

Comparison among echocardiographic predictors. There was no significant difference among areas under the ROC curve for
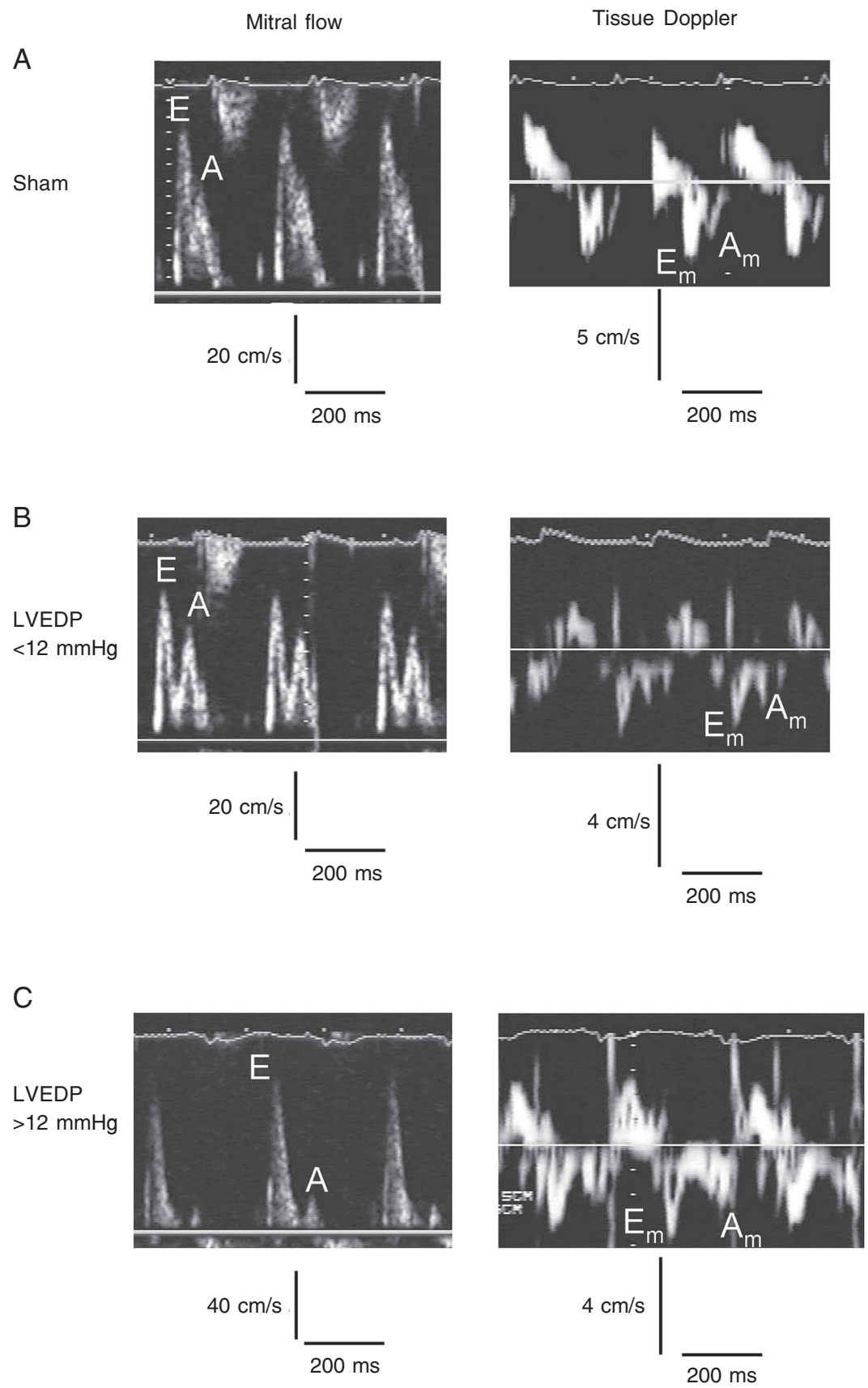

Figure 1. Representative transmitral flow, on the left, and Doppler tissue myocardial mitral annulus velocities, on the right, obtained from sham-operated rats (Sham, A), and from post-myocardial infarction (MI) rats with normal $(B)$ or elevated left ventricular end-diastolic pressure (LVEDP; C). Observe that both sham operated rat and rat with $\mathrm{MI}$ and normal LVEDP displayed similar E/A ratios, whereas rat with $\mathrm{Ml}$ and high LVEDP displayed increased $E / A$ ratio. On the other hand, $E_{m} / A_{m}$ ratios were similar among examples from these three groups. $A=$ peak late diastolic LV filling velocity; $A_{m}=$ peak late diastolic myocardial velocity; $E$ = peak early diastolic LV filling velocity; $E_{m}=$ peak early diastolic myocardial velocity. 
the parameters that could predict high LVEDP.

After multiple linear regression analysis including all echocardiographic parameters with a significant linear correlation with LVEDP, only the $\mathrm{E} / \mathrm{A}(\mathrm{P}=0.006)$ and $\mathrm{E} / \mathrm{E}_{\mathrm{m}}$ $(\mathrm{P}=0.01)$ ratios were identified as independently associated with LVEDP.

Table 2. Pearson's correlations between echocardiographic parameters and left ventricular enddiastolic pressure.

$\mathrm{R}$

\begin{tabular}{lc}
\hline MI size & $0.54^{*}$ \\
LVDd & $0.64^{*}$ \\
LVDs & $0.52^{*}$ \\
LA & 0.36 \\
LVFAC & $-0.65^{*}$ \\
DT & 0.31 \\
IVRT & -0.09 \\
E/A & $0.75^{*}$ \\
LV MPI & 0.17 \\
$S_{m}$ & -0.22 \\
$E_{m}$ & -0.40 \\
$A_{m}$ & -0.25 \\
$E_{m} / A_{m}$ & -0.14 \\
E/E $_{m}$ & $0.75^{*}$ \\
\hline
\end{tabular}

For abbreviations, see legend to Table 1. ${ }^{*} \mathrm{P}<0.05$.

Table 3. Analysis of receiver-operating characteristic (ROC) curves for the identification of high left ventricular end-diastolic pressure after myocardial infarction (MI).

\begin{tabular}{lccccc}
\hline & Cut-off & $\begin{array}{c}\text { Sensitivity } \\
(\%)\end{array}$ & $\begin{array}{c}\text { Specificity } \\
(\%)\end{array}$ & $P$ & $\begin{array}{c}\text { Area under } \\
\text { ROC curve }\end{array}$ \\
\hline MI size (\%) & 19.1 & 72.7 & 80 & 0.08 & 0.73 \\
LVDd (cm) & 0.72 & 81.8 & 80 & 0.02 & 0.78 \\
LVDs (cm) & 0.32 & 90.9 & 60 & 0.08 & 0.73 \\
LA $(\mathrm{cm})$ & 0.41 & 81.8 & 60 & 0.12 & 0.71 \\
LVFAC $(\%)$ & 53.5 & 81.8 & 80 & 0.01 & 0.82 \\
DT $(\mathrm{ms})$ & 43.2 & 72.7 & 80 & 0.10 & 0.72 \\
IVRT $(\mathrm{ms})$ & 55.7 & 81.8 & 40 & 0.87 & 0.53 \\
E/A & 1.77 & 90.0 & 80 & 0.001 & 0.84 \\
LV MPI & 0.57 & 60.0 & 75 & 0.45 & 0.62 \\
$\mathrm{~S}_{\mathrm{m}}(\mathrm{cm} / \mathrm{s})$ & 1.98 & 36.4 & 80 & 0.87 & 0.53 \\
$\mathrm{E}_{\mathrm{m}}(\mathrm{cm} / \mathrm{s})$ & 3.63 & 100 & 60 & 0.26 & 0.67 \\
$\mathrm{~A}_{\mathrm{m}}(\mathrm{cm} / \mathrm{s})$ & 2.31 & 54.5 & 80 & 0.53 & 0.60 \\
$\mathrm{E}_{\mathrm{m}} / \mathrm{A}_{\mathrm{m}}$ & 1.25 & 63.6 & 60 & 0.32 & 0.65 \\
$\mathrm{E}_{\mathrm{E}} \mathrm{E}$ & 20.4 & 81.8 & 80 & 0.0001 & 0.87 \\
\end{tabular}

For abbreviations, see legend to Table 1.

\section{Discussion}

The main finding of the present study is that DE can identify rats with high LVEDP soon after experimentally induced MI. Among several parameters analyzed, the E/ A ratio and $\mathrm{E} / \mathrm{E}_{\mathrm{m}}$ ratio were the best predictors. Moreover, the $\mathrm{E} / \mathrm{A}$ and $\mathrm{E} / \mathrm{E}_{\mathrm{m}}$ ratios were independently associated with LVEDP and the E/A ratio was as effective as the more sophisticated tissue Doppler analysis for the identification of rats with high LVEDP by ROC curve analysis.

These findings are unique in that they relied on the simultaneous assessment of invasive pressure and echocardiographic measurements made just one week after MI. Previous studies that addressed this issue compared DE parameters to non-simultaneously obtained invasive hemodynamic data at a chronic stage after MI (9-12). The importance of LV function analysis soon after MI is emphasized by the fact that in many studies using this model the experimental drug was started as early as 2 days after surgery $(4,5,19)$. Therefore, the present study provides important information permitting selection of animals with recent MI and severe LV dysfunction, expressed as elevated LVEDP, yielding randomization of homogenous populations before the start of the experimental therapy to be evaluated.

The MI population studied here presented average depressed cardiac performance, as demonstrated by elevated LVEDP and decreased LVFAC, with early changes in heart geometry demonstrated by chambers of increased diameter and an elevated RV weight index. However, there was a wide variation in MI size (from 13.4 to $52 \%$ of LV) and cardiac performance with LVEDP ranging from normal $(3.4 \mathrm{mmHg})$ to very high values $(23.4 \mathrm{mmHg})$, indicating the need for a detailed examination of $\mathrm{LV}$ function postMI before animal randomization.

Although chamber diameters were already enlarged 1 week after MI, only LVDd 
was a significant predictor of high LVEDP. A previous study using rats 6 weeks post-MI has shown that LA diameter could be useful to distinguish between post-MI rats with and without HF (10). Indeed, in humans, LA size or volume is closely associated with raised LV filling pressures (20) and serum natriuretic peptide (21). However, chamber diameters, except for LVDd, were not good predictors of high LVEDP at the early time point studied in the present investigation, a fact probably due to the incomplete LV remodeling process $(2,22)$. It is possible that in the chronic phase LV diameters could be good predictors of high LVEDP, but this was not tested in previous studies $(9,11)$. Another important point is that MI size measured by echocardiography was not a good predictor of high LVEDP soon after MI. Thus, MI size estimation alone cannot guarantee an accurate description of the hemodynamic condition of the animal.

The E/A ratio was the best classical DE parameter for identifying animals with high LVEDP after MI, with a large area under the ROC curve, and a good linear correlation with LVEDP. In fact, several other studies have described an increased E/A ratio both at early $(23,24)$ and late (23) stages after MI, as well as significant correlations between E/A ratio and LVEDP (9). It could be argued that in this early phase soon after MI, diastolic dysfunction should be characterized by a pattern of delayed relaxation with an E/A ratio under 1. However, diastolic dysfunction in MI-induced $\mathrm{HF}$ in rats typically presents an elevation in E/A ratio (9,22,23-25), as early as 2 (24) or 3 days after MI (25) and, to our knowledge, without a distinct phase of an E/A ratio below 1 preceding the development of a high E/A ratio.

The excellent predictive value of the E/A ratio is not surprising. The high LA pressure present at the moment of mitral valve opening determines high $\mathrm{E}$ wave velocities in animals with $\mathrm{MI}$ in heart failure. At the end of diastole, the elevated LVEDP associated with the loss of LV compliance after MI due to myocardial edema (2) opposes LA contraction, thereby considerably decreasing the velocity of blood flow from the LA into the $\mathrm{LV}$. As a result, the E/A ratio was significantly higher in animals with MI and HF than in Sham controls, and further increased as LVEDP rose. The other pulsed Doppler parameters were unable to accurately identify elevated LVEDP in rats after MI, although there was a significant increase in isovolumic relaxation time after MI.

Although tissue Doppler has been demonstrated to be a powerful tool in the study of diastolic function and in the estimation of LVEDP in humans (26-28), in the present study, the $E / E_{m}$ ratio was the only tissue Doppler parameter that accurately identified high LVEDP soon after MI. Moreover, the $\mathrm{E} / \mathrm{E}_{\mathrm{m}}$ ratio was not superior to the $\mathrm{E} / \mathrm{A}$ ratio
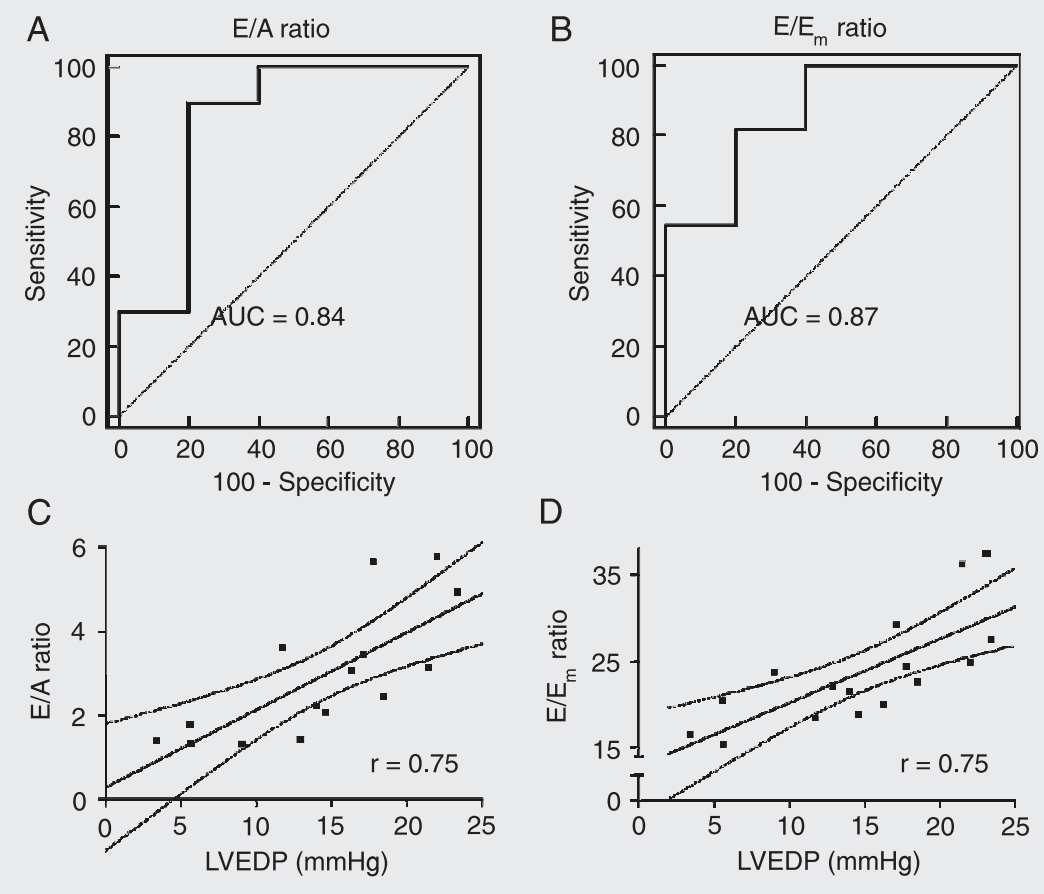

Figure 2. Receiver-operating characteristic curves of $E / A(A)$ and $E / E_{m}(B)$ ratios for identifying high left ventricular end-diastolic pressure (LVEDP) in rats with myocardial infarction (MI). Observe the large area under the curve (AUC) for both variables. Note the similar good linear correlations by univariate analysis between LVEDP and E/A (C) and E/ $E_{m}(D)$ ratios. $A=$ peak late diastolic LV filling velocity; $A_{m}=$ peak late diastolic myocardial velocity; $E$ = peak early diastolic LV filling velocity; $E_{m}=$ peak early diastolic myocardial velocity. 
in predicting high LVEDP. In fact, both were independently associated with LVEDP in the MI group. These findings are in contrast to another study (9), in which the $\mathrm{E} / \mathrm{E}_{\mathrm{m}}$ ratio was considered to be the best parameter for estimating LVEDP. However, in this last study echocardiographic and hemodynamic measurements were not made simultaneously and the data were obtained 3 months after MI. Our simultaneous assessment demonstrated that pulsed Doppler offers similar accuracy compared to tissue Doppler parameters, in addition to the advantage of greater ease of measurement, in identifying rats with $\mathrm{MI}$-induced $\mathrm{HF}$ and elevated LVEDP soon after MI.

LV MPI has been the focus of recent studies that addressed the use of DE to assess LV function post-MI in rats $(11,12)$. LV MPI significantly increased after MI and correlated with LVEDP $(11,12)$, and in one of these studies LVEDP was an independent determinant of LV MPI (12). In the present study, LV MPI also increased after MI, in agreement with a previous study by our group that showed a shorter ejection time and a prolonged isovolumic contraction time contributing to an increased LV MPI in rats with moderate and large MI (15). However, in the present study, the small areas under the ROC curves and the weak correlation coefficients of LV MPI against LVEDP at an early stage after MI illustrate that this parameter is not useful for identifying animals with high LVEDP soon after MI.

\section{Limitations}

Limitations of this study may include the kind of anesthesia used and the use of fluidfilled catheters. Ketamine-xylazine anesthesia is associated with depressed heart rate and a negative influence on $\mathrm{LV}$ ejection fraction in rodents (29-31). However, a longlasting anesthesia was more suitable to the long protocol of this study that included two different procedures (LV catheterization and echocardiography). Moreover, a slower heart rate facilitated the identification of both the $\mathrm{E}$ and $\mathrm{A}$ waves of mitral inflow, whereas higher heart rates achieved with other anesthetics usually result in fusion of $\mathrm{E}$ and $\mathrm{A}$ waves.

Another possible methodological limitation was the use of fluid-filled catheters instead of micromanometers. High-fidelity pressure records allowed by micromanometers are important for assessing isovolumic contraction and relaxation. Indeed, during these periods the LV pressure curve includes high frequency fundamental components able to promote the resonant phenomenon. The end-diastolic pressure comprises low frequency components, not exposed to resonant interference and almost unaffected by dumping. Additionally, the good quality of the physical characteristics of our manometric system should be emphasized, as natural resonant frequency of $52 \mathrm{~Hz}$ and dumping degree of 0.69 assure reliable evaluations of LV pressure (14) at the range of heart rate attained in our animals, approximately $4 \mathrm{~Hz}$.

Using simultaneous hemodynamic and echocardiographic assessments, the present study demonstrated that DE could accurately identify rats with high LVEDP, and therefore in HF, soon after experimentally induced MI. Among several Doppler echocardiographic parameters, the $\mathrm{E} / \mathrm{A}$ and $\mathrm{E} / \mathrm{E}_{\mathrm{m}}$ ratios were the best predictors of LVEDP with independent association with LVEDP. Importantly, the E/A ratio was as good as tissue Doppler parameters, including the E/ $E_{m}$ ratio. These results form the basis for future studies using longitudinal assessment of experimental therapies in this HF model.

\section{Acknowledgments}

We thank Anatiana Fiuza Satiro Siebra Souto for technical assistance and Dr. Michelle Kittleson (Cardiology Division, The Johns Hopkins Medical Institutions), for a careful review of the manuscript. 


\section{References}

1. Pfeffer MA, Pfeffer JM, Fishbein MC, Fletcher PJ, Spadaro J, Kloner RA, et al. Myocardial infarct size and ventricular function in rats. Circ Res 1979; 44: 503-512.

2. Pfeffer JM, Pfeffer MA, Fletcher PJ, Braunwald E. Progressive ventricular remodeling in rat with myocardial infarction. Am J Physiol 1991; 260: H1406-H1414.

3. Pfeffer JM. Progressive ventricular dilation in experimental myocardial infarction and its attenuation by angiotensin-converting enzyme inhibition. Am J Cardiol 1991; 68: 17D-25D.

4. Ahmet I, Lakatta EG, Talan MI. Pharmacological stimulation of beta2adrenergic receptors (beta2AR) enhances therapeutic effectiveness of beta1AR blockade in rodent dilated ischemic cardiomyopathy. Heart Fail Rev 2005; 10: 289-296.

5. de Resende MM, Kauser K, Mill JG. Regulation of cardiac and renal mineralocorticoid receptor expression by captopril following myocardial infarction in rats. Life Sci 2006; 78: 3066-3073.

6. Davani S, Marandin A, Mersin N, Royer B, Kantelip B, Herve P, et al. Mesenchymal progenitor cells differentiate into an endothelial phenotype, enhance vascular density, and improve heart function in a rat cellular cardiomyoplasty model. Circulation 2003; 108 (Suppl 1): II253-II258.

7. Min JY, Yang $\mathrm{Y}$, Sullivan MF, Ke Q, Converso KL, Chen $\mathrm{Y}$, et al. Long-term improvement of cardiac function in rats after infarction by transplantation of embryonic stem cells. J Thorac Cardiovasc Surg 2003; 125: 361-369.

8. Solomon SD, Greaves SC, Rayan M, Finn P, Pfeffer MA, Pfeffer JM. Temporal dissociation of left ventricular function and remodeling following experimental myocardial infarction in rats. J Card Fail 1999; 5: 213-223.

9. Prunier F, Gaertner R, Louedec L, Michel JB, Mercadier JJ, Escoubet B. Doppler echocardiographic estimation of left ventricular end-diastolic pressure after MI in rats. Am J Physiol 2002; 283: H346-H352.

10. Sjaastad I, Sejersted OM, llebekk A, Bjornerheim R. Echocardiographic criteria for detection of postinfarction congestive heart failure in rats. J Appl Physiol 2000; 89: 1445-1454.

11. Morgan EE, Faulx MD, McElfresh TA, Kung TA, Zawaneh MS, Stanley WC, et al. Validation of echocardiographic methods for assessing left ventricular dysfunction in rats with myocardial infarction. Am J Physiol 2004; 287: H2049-H2053.

12. Jegger $D$, Jeanrenaud $X$, Nasratullah $M$, Chassot $P G$, Mallik $A$, Tevaearai $\mathrm{H}$, et al. Noninvasive Doppler-derived myocardial performance index in rats with myocardial infarction: validation and correlation by conductance catheter. Am J Physiol 2006; 290: H1540H1548.

13. Kanashiro RM, Nozawa E, Murad N, Gerola LR, Moises VA, Tucci PJ. Myocardial infarction scar plication in the rat: cardiac mechanics in an animal model for surgical procedures. Ann Thorac Surg 2002; 73: 1507-1513.

14. Fry DL. Physiologic recording by modern instruments with particular reference to pressure recording. Physiol Rev 1960; 40: 753-788.

15. Cury AF, Bonilha A, Saraiva R, Campos O, Carvalho AC, De Paola $A A$, et al. Myocardial performance index in female rats with myocardial infarction: relationship with ventricular function parameters by Doppler echocardiography. J Am Soc Echocardiogr 2005; 18: 454460.

16. Burrell LM, Chan R, Phillips PA, Calafiore P, Tonkin AM, Johnston $\mathrm{Cl}$. Validation of an echocardiographic assessment of cardiac function following moderate size myocardial infarction in the rat. Clin Exp
Pharmacol Physiol 1996; 23: 570-572.

17. Nozawa E, Kanashiro RM, Murad N, Carvalho AC, Cravo SL, Campos O, et al. Performance of two-dimensional Doppler echocardiography for the assessment of infarct size and left ventricular function in rats. Braz J Med Biol Res 2006; 39: 687-695.

18. Boluyt MO, Converso K, Hwang HS, Mikkor A, Russell MW. Echocardiographic assessment of age-associated changes in systolic and diastolic function of the female F344 rat heart. J Appl Physiol 2004; 96: 822-828.

19. Berthonneche C, Sulpice T, Tanguy S, O'Connor S, Herbert JM, Janiak $P$, et al. AT1 receptor blockade prevents cardiac dysfunction after myocardial infarction in rats. Cardiovasc Drugs Ther 2005; 19 : 251-259.

20. Simek CL, Feldman MD, Haber HL, Wu CC, Jayaweera AR, Kaul S. Relationship between left ventricular wall thickness and left atrial size: comparison with other measures of diastolic function. $\mathrm{J} \mathrm{Am}$ Soc Echocardiogr 1995; 8: 37-47.

21. Lim TK, Ashrafian H, Dwivedi G, Collinson PO, Senior R. Increased left atrial volume index is an independent predictor of raised serum natriuretic peptide in patients with suspected heart failure but normal left ventricular ejection fraction: Implication for diagnosis of diastolic heart failure. Eur J Heart Fail 2006; 8: 38-45.

22. Litwin SE, Katz SE, Morgan JP, Douglas PS. Serial echocardiographic assessment of left ventricular geometry and function after large myocardial infarction in the rat. Circulation 1994; 89: 345-354.

23. Litwin SE, Katz SE, Morgan JP, Douglas PS. Effects of propranolol treatment on left ventricular function and intracellular calcium regulation in rats with postinfarction heart failure. Br J Pharmacol 1999; 127: 1671-1679.

24. Hanatani A, Yoshiyama M, Kim S, Omura T, Ikuno Y, Takeuchi K, et al. Assessment of cardiac function and gene expression at an early phase after myocardial infarction. Jpn Heart J 1998; 39: 375-388.

25. Omerovic E, Bollano E, Mobini R, Kujacic V, Madhu B, Soussi B, et al. Growth hormone improves bioenergetics and decreases catecholamines in postinfarct rat hearts. Endocrinology 2000; 141: 4592-4599.

26. Nagueh SF, Kopelen HA, Zoghbi WA. Feasibility and accuracy of Doppler echocardiographic estimation of pulmonary artery occlusive pressure in the intensive care unit. Am J Cardiol 1995; 75: 1256-1262.

27. Nagueh SF, Mikati I, Kopelen HA, Middleton KJ, Quinones MA, Zoghbi WA. Doppler estimation of left ventricular filling pressure in sinus tachycardia. A new application of tissue Doppler imaging. Circulation 1998; 98: 1644-1650.

28. Nagueh SF, Middleton KJ, Kopelen HA, Zoghbi WA, Quinones MA. Doppler tissue imaging: a noninvasive technique for evaluation of left ventricular relaxation and estimation of filling pressures. $J \mathrm{Am}$ Coll Cardiol 1997; 30: 1527-1533.

29. Chaves AA, Weinstein DM, Bauer JA. Non-invasive echocardiographic studies in mice: influence of anesthetic regimen. Life Sci 2001; 69: 213-222.

30. Rottman JN, Ni G, Khoo M, Wang Z, Zhang W, Anderson ME, et al. Temporal changes in ventricular function assessed echocardiographically in conscious and anesthetized mice. J Am Soc Echocardiogr 2003; 16: 1150-1157.

31. Kawahara Y, Tanonaka K, Daicho T, Nawa M, Oikawa R, Nasa Y, et al. Preferable anesthetic conditions for echocardiographic determination of murine cardiac function. J Pharmacol Sci 2005; 99: 95104. 


\section{$\forall$ PeproTech Inc.}

\section{Developing \& Manufacturing Recombinant Cytokines!}

Since 1988, PeproTech has been dedicated exclusively to providing life science research with the highest quality cytokine products. Using stateof-the-art facilities, proprietary technologies and devoted personnel, PeproTech has been successful in developing an extensive line of recombinant human, murine and rat cytokines as well as a complementary line of monoclonal and polyclonal antibodies. PeproTech's products are offered to researchers at unmatched prices and are available in quantities ranging from a few micrograms to several grams. Orders for bulk amounts are entitled for significant discounts. Please inquire!
PeproTech's Products include:

- Interleukins \& other Immunoregulatory Cytokines

- TNF Ligands and soluble receptors

- Growth Factors

- Chemokines

- Adipokines

- Neurotrophins

- Angiogenic Cytokines

- Bone Morphogenetic Proteins

- Hematopoietic Factors

- Monoclonal Antibodies and Polyclonal/Biotinylated Antibodies

- ELISA Development Kits

Our focus continues to be on the development of more products, with special emphasis on the development of newly discovered cytokines. We welcome suggestions from researchers. We believe that together we can be better, and encourage you to communicate to us your particular research needs.

\section{PeproTech Worldwide}

In America:

PeproTech Inc.

Princeton Business Park:

5 Crescent Ave.

P.O. Box 275

Rocky Hill, NJ 08553-0275

Tel: (800) 436-9910

(609) 497-0253

Fax: (609) 497-0321

email: info@peprotech.com

www.peprotech.com

In Europe \& Japan:

\section{PeproTech EC Ltd.}

PeproTech House

29 Margravine Road

London W6 8LL

England

Tel: $\quad$ +44 (0)207610 3062

Fax: +44(0)2076103430

email: info@peprotechec.com

www.peprotechec.com
In Canada:

PeproTech Canada, Inc.

2211 Riverside Drive

Suite 403

Ottawa, Ontario K1H 7 X5

Canada

Tel: $613-739-0083$, or 866-846-2847

Fax: 613-739-5850

email: peprotechcanada@on.aibn.com

www. peprotech.com

\section{In Latin America:}

\section{PeproTech México, S.A.DEC.V.}

Juan Enriquez No. 128

Altos 2/A

Colonia Flores Magón

91900 Veracruz, Ver.

México

Tel: +52-229-9312355

Fax: +52-299-9312352

email: pepromex@prodigy.net.mx

www.peprotech.com
In Asia, Africa, Australia

\& New Zealand:

\section{Cytolab Ltd.}

Rehovot, Israel

Tel: $\quad$ +972(0) 89460948

Fax: $\quad+972(0) 89460861$

email: info@cytolab.com

www.peprotech.com

In South America:

PeproTech Brazil FUNPEC

Rua Hudson 655

14.024-000 Ribeirao Preto, SP

Brazil

Tel/FAX: 55 (16) 6201251

email: funpecrp@uol.com.br

www.funpecrp.com.br

At NIH (National Institute of Health):

\section{PeproTech at NIH}

Ms. Sheila Cook, Sales Representative 4900 General Anderson Ct.

Sharpsburg, MD 21782

Tel: (301) 432-7858

Cell: (240) 675-6869

email: sheila@peprotech.com

www.peprotech.com 